\title{
Screening of HIV and Identifying Risk Factors among Premedical Students, Kafr El-Sheikh University, Egypt
}

\author{
Ibrahim Amer ${ }^{1}$, Kariman Ahmed Eshra ${ }^{2}$, Shimaa Elsharawy ${ }^{3}$ \\ ${ }^{1}$ Department of Hepatology, Gastroenterology and Infectious diseases, Faculty of \\ Medicine, Kafrelshiekh University. \\ ${ }^{2}$ Department of Microbiology and Immunology, Faculty of Medicine, Tanta University. \\ ${ }^{3}$ Department of Tropical Medicine \& Infectious Diseases, Faculty of Medicine, Tanta \\ University.
}

Corresponding Author Amer, Ibrahim

Mobile: 00201063307637

\section{E mail:}

hema.amer30@gmail.c om

Key words:

Egypt, HIV, Kafr El Sheikh University, premedical students)
Background and study aim: HIV is a global public health problem. Many people in Egypt are afraid to get tested for HIV so the real situation remains unknown. The aim of this article was to determine HIV status and HIV related risk factor among Egyptian premedical students.

Patients and Methods: A cross-sectional survey using a self-administered structured questionnaire was used to collect data to identify HIV related risk factor beside serosurvey to detect HIV antibodies among 737 from a total of 1123 pre medical students in Kafr El Sheikh University (KFU) who agreed to participate in the study.
Results: The mean age of screened students was $18 \pm 0.26$ years. In total, 333 $(45.2 \%)$ were males and $403(54.8 \%)$ were females. Using HIV antibody testing; we did not find any positive HIV cases in our study. (7.5\%) underwent any surgical procedure, $(0.4 \%)$ received blood or blood product transfusions, and $(0.1 \%)$ shared needle or syringe with others. While $(42.8 \%)$ shared scissors, razors, and nail clippers with others and $(57.3 \%)$ went ever to the dentist but none of them had any sexual relationships or HIV patient within the family.

Conclusion: We detected no cases of HIV or risky behaviors among Egyptian premedical students.

\section{INTRODUCTION}

The human immune deficiency virus (HIV) is a global problem for public health [1]. The Middle East and North Africa (MENA) area has the world's lowest (less than 0.1 percent) HIV prevalence; in 2018, 240,000 people were living with HIV [2]. MENA is one of only two areas where the incidence of HIV and death from AIDS is on the increase [3]. According to UNAIDS 2019, Egypt has a low national prevalence of $<0.1 \%$ among the general population, largely due to conservative culture, and there are about 22,000 people living with HIV in Egypt at the moment [2]. Nevertheless, HIV prevalence rates in Egypt rose tenfold between 2006 and 2011 [4]. The incidence of new infections among main populations at a high risk of exposure including drug users, sex workers and men who have sex with men is growing exponentially [5]. Worldwide, stigma and discrimination (S\&D) associated with the HIV epidemic continue to persist and both have devalued PLHIV excessively by exclusion and marginalization $[\mathbf{6}, \mathbf{7}]$. Most individuals in Egypt are unwilling to get HIV screened due to the current disease's stigma. In the years before 2004, the majority of cases of HIV recorded in Egypt were due to mandatory testing, for example for blood donors, foreigners staying in the country for more than six months, and citizens applying for work permits abroad [8]. Adolescents account for 40 percent of new HIV infections each year and adolescents ' AIDS-related deaths have risen by 50 percent over the last 10 years $[\mathbf{9 , 1 0}]$. 
About five million adolescents and young people between the ages of 10 and 24 are living with HIV globally and an estimated 900,000 adolescents between the ages of 10 and 19 are newly infected each year, placing them at the epicenter of the HIV epidemic [11].

Adolescence is a critical period of developmental, physical and social change, and often requires sexual debut. Reaching teenagers for HIV testing provides an opportunity to determine behaviors to prevent HIV, including routine testing and sex education, and can reduce the incidence of HIV [12].

However, only $11 \%$ of cases of HIV in Egypt are among young people, the early average age of sexual initiation and increasing premarital sex tendencies could increase these rates [13]; this does not mean our countries are immune to HIV spread [14].

Individuals who are not deemed to be a part of high-risk groups appear to have a relative low interest in receiving an HIV test [15]. Despite HIV testing is a routine young people's health care service [16] most college students have never been tested for HIV [17]. Considering the fears of the World Health Organizations about the imminent rise in HIV prevalence, we aimed in this study to determine the necessity for mandatory HIV screening in premedical students and to detect any identified risk factors for HIV infection among them.

\section{MATERIALS AND METHODS}

\section{Study design and setting}

A questionnaire-based, sero-survey observational cross-sectional study was designed to identify HIV related risk factors and HIV status among 737 premedical students of Kafr El-Sheikh University, of 17 to 19 years of age. All of the participants were undergoing one year medical college. Questionnaire was translated into Arabic.

The study was carried out between August 2019 and September 2019 at University Students Hospital, Kafr El-Sheikh University which is founded in Kafr El Sheikh Governorate, one of the Egyptian governorates. It contains 11 cities, including the capital city of Kafr el-Sheikh.

\section{Inclusion criteria}

A sample of 737 premedical students from a total of 1123 students, who participated in questionnaire and HIV screening were included in the study.

\section{Exclusion criteria}

Those students who were not willing to participate in questionnaire and HIV screening were excluded from the study.

\section{Method}

The first part of this study was pre-established questions. The self-administered questionnaire consisted of nine questions: age, sex, history of any surgical procedure, blood transfusions, needle or syringe sharing, scissors, razors, and nail clippers sharing, going to the dentist, travelling abroad, the presence of a patient within the family and presence of any sexual relationships. The questionnaire was based on that has been previously used in a study among secondary school students [18]. The second part of the study was serological tests for antibodies to HIV for all students (rapid HIV: ABON HIV 1/2/O Tri-Line Human Immunodeficiency Virus Rapid Test Device with product code IHIT402W1) by finger stick whole blood specimen: use capillary tube : fill the capillary tube and transfer approximately $5 \mathrm{ml}$ of finger stick whole blood specimen to the specimen well of test device, then add 2 drop of buffer then wait for 10 minutes: if two or three line appear, the result is positive but if one line appears in control region, the result is negative and control line fail to appear in control region, the result is invalid .

\section{Statistical analysis}

Analysis of data was done using SPSS version 20 (Armonk, NY: IBM Corp). Qualitative data were presented as mean $\pm \mathrm{SD}$, while qualitative data were presented as frequency and percentage.

\section{RESULTS}

A total of 737 students, $333(45.2 \%)$ males and $403(54.8 \%)$ females, with a mean age of $18 \pm$ 0.26 years, starting their first year at Kafr ElSheikh University were enrolled in this study. When screened for HIV infection using HIV antibody test, all students were negative. As regard the risk factor of the students; only $7.5 \%$ had history of any surgical procedure. $0.4 \%$ history of blood or blood product transfusions. 
$0.1 \%$ shared needle or syringe while $42.8 \%$ shared scissors, razors, and nail clippers with others. $57.3 \%$ had history of going to the dentist.
$5.3 \%$ had history of travelling abroad. No one had a patient within his family or any sexual relationships (Table 1).

Table (1): Demographics, HIV related risk factors and HIV status of participated students $(\mathrm{n}=736)$.

\begin{tabular}{|c|c|}
\hline Variables & No. $(\%)$ \\
\hline \multicolumn{2}{|l|}{$\overline{\text { Sex }}$} \\
\hline Male & $333(45.2 \%)$ \\
\hline Female & $403(54.8 \%)$ \\
\hline \multicolumn{2}{|l|}{ Age } \\
\hline Mean \pm SD & $18 \pm 0.26$ \\
\hline \multicolumn{2}{|c|}{ History any surgical procedure } \\
\hline Negative & $681(92.5 \%)$ \\
\hline Positive & $55(7.5 \%)$ \\
\hline \multicolumn{2}{|c|}{ History of blood or blood product transfusions } \\
\hline Negative & $733(90.6 \%)$ \\
\hline Positive & $3(0.4)$ \\
\hline \multicolumn{2}{|c|}{ Needle or syringe sharing } \\
\hline Negative & $735(99.9 \%)$ \\
\hline Positive & $1(0.1)$ \\
\hline \multicolumn{2}{|c|}{ Scissors, razors, and nail clippers sharing } \\
\hline Negative & $421(57.2 \%)$ \\
\hline Positive & $315(42.8 \%)$ \\
\hline \multicolumn{2}{|c|}{ Going to the dentist } \\
\hline Negative & $314(42.7 \%)$ \\
\hline Positive & $422(57.3 \%)$ \\
\hline \multicolumn{2}{|c|}{ Travelling abroad } \\
\hline Negative & $697(94.7 \%)$ \\
\hline Positive & $39(5.3 \%)$ \\
\hline \multicolumn{2}{|c|}{ Presence of HIV patient within the family } \\
\hline Negative & $736(100 \%)$ \\
\hline Positive & $0(0.0 \%)$ \\
\hline \multicolumn{2}{|c|}{ Any sexual relationships } \\
\hline Negative & $736(100 \%)$ \\
\hline Positive & $0(0.0 \%)$ \\
\hline \multicolumn{2}{|c|}{ Result of rapid HIV test } \\
\hline Negative & $736(100 \%)$ \\
\hline Positive & $0(0.0 \%)$ \\
\hline
\end{tabular}

\section{DISCUSSION}

Global goals have recently emerged to reduce new adolescent HIV infections by $75 \%$ and AIDS-related deaths by $65 \%$. The global "All In" strategic framework falls in line with the vision of zero AIDS-related deaths and zero prejudice that will end the adolescent epidemic by $2030(10-19$ y) [19, 20]. Egyptian teenagers and young people between 13 and 35 years of age found that only $73.2 \%$ of participates knew about HIV / AIDS and only 35\% knew 3-4 modes of transmission [21]. The widespread adoption of HIV testing among high school students and youth requires more efforts [22]. To our knowledge, this study is novel as no previous study has been performed in Egypt that includes premedical students' HIV status and HIV related risk factor. Few reports were published on the prevalence of HIV among voluntary blood donors in Egypt. In the present study, 100\% of students were negative for HIV testing. This is consistent with Nada and Atwa who found no positive HIV cases in blood bank of Suez Canal University Hospital during the seroprevalence of HIV antibodies among blood donors [23]. Constantine et al also announced that after 2.5 years of HIV serosurvey all Egyptian blood donors had been negative [24]. Moreover, the incidence of HIV antibody reactivity over the period from 2000 to 2005 was found to be $0.0 \%$ in a study conducted by NCI [25] compared to two cases 5 years before [26]. The World Health Organization estimates a rate of $0.15 \%$ among the total Egyptian population. In 2000, only $0.04 \%$ of 16559 voluntarily tested Egyptians 
were positive for HIV [27]. This study confirms the reports of low prevalence of AIDS in Egypt [28]. This is consistent with $0 \%$ prevalence among Jordanian [29] and Turkish [30]. Compared with Tanzania it was $1.5 \%$ [31], and in Republic of Djibouti 1.9\% [32]. In Germany, HIV incidence was $0.82 \%$ in the year 2003 and $0.48 \%$ in 2004 [33]. This can be clarified on the basis that such risky behaviors such as extramarital sexual activities and drug abuse are prohibited by culture and traditions in Egypt [34]. Nonetheless, Omran et al reported a growing trend in HIV reactivity rates among both voluntary donors and family substitute donors at a Blood Bank University Hospital in Cairo during the period 2007-2011 [35]. Moreover, El-Sayed and Mortagy estimated that the use of infected blood and/or blood products is linked to $24 \%$ of confirmed HIV cases. A quarter of reported cases of HIV in Egypt have been iatrogenically infected, particularly in hemodialysis centers [36]. In addition, Soliman et al in their study have enrolled 413 male injection drug users (IDUs) from Cairo to measure HIV prevalence; HIV prevalence was $0.6 \%, 53.0 \%$ reported IDUs with used needles or syringes, out of which $9.4 \%$ reported sex with male partners and $13.2 \%$ reported sex with commercial sex workers [37]. In the present study most of our participants had no risk factor for acquiring HIV except of going to dentists (57.3\%) but all were negative HIV testing. When dental care can be delivered with a high level of safety, provided the infection control requirements are adhered to [38]. This is supported by the study of El-Sayed and Khalifa found that routine use of gloves and the compliance with changing gloves between patients was $100 \%$ among the study groups indicates a high degree of basic infection control practices at Cairo Dental Research Center. This is in agreement of several studies $[\mathbf{3 9}, \mathbf{4 0}, \mathbf{4 1}, \mathbf{4 2}$, and 43]. In addition, a further research on 115 dentists at the Faculty of Dentistry in Mansoura showed good hand washing practices and high knowledge [44]. This illustrates the importance of instrument sterilization and disinfection in dental offices to prevent infection from spreading from patient to patient and from instrument to patient [45]. Also $42.8 \%$ of our participants share Scissors, razors, and nail clippers with others. These results are in agreement with Rehab et al who reported 53\% sharing nail clippers/scissors, 4.7\% sharing shaving instrument and $0 \%$ sharing injection \& syringes of 400 house hold contact to
$\mathrm{HCV}$ patient enrolled to explore intra-familial transmission of HCV in their study [46]. Also, another study reported that shaving at barbershops was at increased risk of $\mathrm{HBV}$ transmission since this is a very common practice among Egyptian men (64.4\% of controls) [47]. As Barbers are generally unaware of the principle of blood-borne transmission, and razors and scissors are used regularly by various customers without sterilization $[48,49]$.

\section{CONCLUSION AND RECOMMENDATION}

The good news is there were no cases of HIV or risky behaviors among Egyptian students in this sample. But more surveys should be considered to monitor and further define the prevalence of this virus among populations in Egypt to can quantify the real situation. Also, we recommend follow up of those HIV negative premedical students which may give an idea about the risk of HIV infection among Egyptian health care workers.

\author{
Abbreviations \\ KFU: Kafr El Sheikh University \\ HIV: The human immune deficiency virus \\ MENA: The Middle East and North Africa \\ UNAIDS: United Nations Programme on HIV/AIDS \\ S\&D: stigma and discrimination \\ BBSS: Biological and Behavioral Surveillance Survey \\ PLHIV: people living with HIV \\ AIDS: Acquired immunodeficiency syndrome \\ NCI: National Cancer Institute \\ IDUs: injection drug users \\ HCV: hepatitis B virus \\ HBV: hepatitis B virus
}

\section{Ethical considerations:}

The research steps were explained and the permission for conducting the research was obtained from the approving authority, Faculty of medicine, Kafr El-Sheikh University, Egypt.

Conflict of interest: The authors declare that they have no competing interests.

Financial disclosure: We thank the students and KFU who participated and cooperated in the study. 


\section{REFERENCES}

1. Kallings LO. The first postmodern pandemic: 25 years of HIV/ AIDS. J. Intern. Med. 2008; 263(3): 218-43.

2. UNAIDS 'AIDSinfo' (accessed February 2019).

3. The Joint United Nations Programme on HIV/AIDS (UNAIDS). Global AIDS update 2018. UNAIDS. Geneva; 2018.

4. UNICEF Egypt - HIV/AIDS - Context". Www.unicef.org. Retrieved 2017-11-08.

5. HIV/AIDS Biological and Behavioral Surveillance Survey. Cairo, Egypt: Family Health International; 2010.

6. UNAIDS Fact sheet on stigma and discrimination. Dec, 2003. [Accessed January 27, 2017]. Available from: http://data.unaids.org/publications/FactSheets03/fs_stigma_discrimination_en.pdf.

7. UNAIDS Global report; UNAIDS report on the global AIDS epidemic. 2013. [Accessed February 12, 2017]. Available from: http://www.unaids.org/en/resources/documents/2 013/20130923_UNAIDS_Global_Report_2013.

8. HIV/AIDS services for refugees in Egypt. EBSCOhost". Eds.b.ebscohost.com. Retrieved 2017-11-09.

9. UNAIDS. Young People and HIV. New York: UNAIDS, 2012.

10. Auld AF, Agolory SG, Shiraishi RW, Mangen FW, Kwesigabo G, Mulenga $M$, et al. Antiretroviral therapy enrollment characteristics and outcomes among HIV infected adolescents and young adults compared with older adultsseven African countries, 2004-2013. MMWR Morb Mortal Wkly Rep. 2014; 63:1097-1103.

11. UNAIDS. Global Report: UNAIDS Report on the Global AIDS Epidemic 2013. Available at: www.unaids.org/sites/ default/files/media_asset/ UNAIDS_Global_Report_2013_en_1.pdf (Last accessed April 27, 2016).

12. Rosenberg NE, Westreich D, Barnighausen $\mathrm{T}$, Miller WC, Behets F, Maman S, et al. Assessing the effect of HIV counselling and testing on HIV acquisition among South African youth. Aids.2013; 27:2765-2773.

13. Boutros S, Skordis J. HIV/AIDS surveillance in Egypt: Current status and future challenges/Surveillance du VIH/sida en égypte: Situation actuelle ET défis à venir. Eastern Mediterranean Health Journal. 2010; 16(3): 251-8.

14. Kandela P. Arab nations: attitudes to AIDS. Lancet. 1993; 341:884-885.

15. Mays RM, Sturm LA, Rasche JC, Cox DS, Cox $\mathrm{AD}$, Zimet GD. Use of drawings to explore U.S. women's perspectives on why people might decline HIV testing. Health Care Women Int. 2011; 32:328-343.

16. Ibrahim M, Ipadeola O, Adebayo S, Fatusi A. Socio-demographic determinants of HIV counseling and testing uptake among young people in Nigeria. Int J Prev Treat. 2013; 2(3):23-31.

17. 17. Lin CA, Roy D, Dam L, Coman EN. College students and HIV testing: cognitive, emotional self-efficacy, motivational and communication factors. J Commun Healthc. 2017; 10(4):250259.

18. Shinde M, Trivedi A, Shinde A, Mishra S K. A study of awareness regarding HIV/AIDS among secondary school students. Int J Community Med Public Health. 2016; 3(6):1461-1465

19. UNAID and UNICEF, 2016:"ALL IN" to end the adolescent AIDs epidemic. A Progress report. Geneva: Joint United Nations Program on HIV/AIDS. Available at:http://www.unaids.org/ sites/default/files/media_asset/ALLIN2016Progr essReport_en.pdf

20. Global AIDS Monitoring, 2018: Country progress report-Egypt: Available at: http://www.unaids.org/sites/default/files/country /documents/EGY_2018_countryreport.pdf

21. Roushdy R and Sieverding M. Panel Survey of Young People in Egypt (SYPE): Generating Evidence for Policy and Programs. Cairo, Egypt: Population Council, 2015.

22. Centers for Disease Control and Prevention. HIV among youth. 2014. Available at: http:// www. cdc. gov/ hiv/ risk/ age/ youth/ . Accessed June 22,2015

23. Nada HA, Atwa M. Seroprevalence of HBV, HCV, HIV and syphilis markers among blood donors at Suez Canal University Hospital Blood Bank. Blood Disord Transfus. 2013; 5: 177.

24. Constantine NT, Sheba MF, Watts DM, Farid Z, And Kamal M. HIV infection in Egypt: two and a half year surveillance. J Trop Med Hyg. 1990 Apr; 93(2):146-50.

25. Eissa SA, Abdel Meguid LM, Ebeid SM, Abou Elfetouh RM, Abdel Moneim GM. National Cancer Institute Experience in Healthy Egyptian Blood Donors as Regards Blood Group Frequencies and Seroprevalence of Hepatitis B Virus, Hepatitis C Virus \& HIV: 10 Year Evaluation. J Egypt Natl Canc Inst.2007; 19: 7176.

26. Soheir AE, Lobna MA, Samir ME, Sherief AAN, Mahmud DF. Prevalence of anti-HIV, HBs-Ag and anti-HCV reactivity in different categories of Egyptian blood donors: Experience of the National Cancer Institute in the last 5 years. J Egypt Nat Cancer Inst.2002; 14: 217221. 
27. El-Sayed N, Aon M, Mortagy I. Assessment of the HIV/AIDS situation and response in Egypt. Cairo, National AIDS Programme, Ministry of Health and Population and the Expanded Theme Group on HIV/AIDS, 2004.

28. Abdel latif S, Mostafa L, Ebeid SM, Abou Elfetouh RM, Abdel Moneim GM, et al. National Cancer Institute Experience in Healthy Egyptian Blood Donors as Regards Blood Group Frequencies and Seroprevalence of Hepatitis B Virus, Hepatitis C Virus \& HIV: 10 Year Evaluation. J Egypt Nat Canc Inst.2007; 19: 7176.

29. Abed Al-Gani F. Prevalence of HBV, HCV and HIV-1, 2 infections among blood donors in Prince Rashed Ben Al-Hassan Hospital in North Region of Jordan. Int J Biol Med Res.2011; 2: 912-916.

30. Afsar I, Gungor S, Sener AG, Yurtsever SG. the prevalence of HBV, HCV and HIV infections among blood donors in Izmir, Turkey. Indian $J$ Med Microbiol.2008; 26: 288-289.

31. Matee MI, Magesa PM, Lyamuya EF. Seroprevalence of human immunodeficiency virus, hepatitis $\mathrm{B}$ and $\mathrm{C}$ viruses and Syphilis infections among blood donors at the Muhimbili National Hospital in Dares Salaam, Tanzania. BMC Public Health. 2006, 30: 6-21.

32. Dray X, Dray-Spira R, Bronstein JA, Mattera D. Prevalence of HIV, hepatitis B and hepatitis C, in blood donors in the Republic of Djibouti. Med Trop. 2005; 65 (1): 39-42.

33. Offergeld R, Ritter S, Faensen D, Hamouda O. Infection epidemiological data among blood donors in Germany 2003-2004. Report of Robert Koch Institute in accordance with Article 22 of the Transfusion Act Bund Gesun. 2005; 48 (11): 1273-87.

34. Country profile, HIV/AIDS, Egypt. Cairo, US Agency for International Development, Bureau for Global Health, 2004 (http://pdf.usaid.gov/pdf_docs/PNADA672.pdf, accessed 10 April, 2005).

35. Omran D, Hussein EA, Nagib M. Safety of Blood Transfusion: An Egyptian Study. J Infect Dis Ther.2013; 1:124.

36. Initiative for HIV voluntary counseling and testing. Cairo, Ministry of Health and Population 2003.

37. Soliman C, Rahman IA, Shawky S, Bahaa T, Elkamhawi S, EL Sattar AA, et al. HIV prevalence and risk behaviors of male injection drug users in cairo, Egypt. AIDS. 2010; 24 SUPPL 2:S33-8.
38. El-Sayed A.K and Khalifa GA. Dental Health Care Workers at Cairo Dental Research Center: Do They Need Further Training on Infection Control Strategy to Prevent Viral Hepatitis Transmission. International Journal of Advanced Research. 2015; 10(3): 572 - 579.

39. Barakat, S.H., and El-Bashir N. Hepatitis C virus infection among healthy Egyptian children: Prevalence and risk factors. J. Viral Hepat.2011; 18(11):779-784.

40. Dahiya, P., Kamal, R., Sharma, V., and Kaur, S. "Hepatitis" - Prevention and management in dental practice. J. Educ. Health Promot.2015; 4:33.

41. Kalil, K.A., Farghally, H.S., Hassanein, K.M., Abd-Elsayed, A.A., Hassanein, F.E. Hepatitis C virus infection among paediatric patients attending University of Assiut Hospital, Egypt. East Mediterr. Health. J.2010; 16(4):356-361.

42. Saleh, D.A., Shebl, F., Abdel-Hamid, M., Narooz, S., Mikhail, N., El-Batanony, et al. Incidence and risk factors for hepatitis $\mathrm{C}$ infection in a cohort of women in rural Egypt. Trans. R. Soc. Trop. Med. Hyg.2008; 102(9):921- 928.

43. Thomas, M.V., Jarboe, G., and Frazer, R.Q. Infection control in the dental office. Dent. Clin. North. Am.2008; 52(3):609-628.

44. EL -Adawi N M , Khashabe E O, Hegazy S. Hand hygiene knowledge and practice among dentists in Mansoura Faculty of Dentistry, Egypt Annals of medical and biomedical sciences. 2016; 2 (1): 9-14.

45. Baseer MA, Rahman G, Yassin MA. Infection control prac-tices in dental school: a patient perspective from SaudiArabia. Dent Res J (Isfahan) 2013; 10:25-30.

46. Ahmed RA, EL-Shafei MH, Abou el-ata OA, EL-Derwi DA, EL-Dusoki HH, Atta NH. Exploring Intrafamilial Transmission Risk Factors of Hepatitis C Virus: An Egyptian Insight. Cairo Univ.2015; 83(2): 313-323.

47. Jimenez AP, Sharaf El-Din N, El-Hoseiny M, El-Daly M, Abdel-Hamid M, El Aidi S, et al. Community transmission of hepatitis $\mathrm{B}$ virus in Egypt: results from a case-control study in Greater Cairo, International Journal of Epidemiology.2009; 38(3): 757-765.

48. Khaliq AA, Smego RA. Barber shaving and blood-borne disease transmission in developing countries. S Afr Med J. 2005; 95:94, 96.

49. Khandait DW, Ambadekar NN, Vasudeo ND. Knowledge and practices about HIV transmission among barbers of Nagpur City. Indian J Med Sci. 1999; 53:167-71. 